\title{
Nephrolithiasis-induced end stage renal disease
}

This article was published in the following Dove Press journal: International Journal of Nephrology and Renovascular Disease 9 March 2010

Number of times this article has been viewed

\author{
M Ounissi' \\ T Gargueh ${ }^{2}$ \\ M Mahfoudhi' \\ K Boubaker' \\ H Hedri' \\ R Goucha' \\ E Abderrahim' \\ F Ben Hamida' \\ T Ben Abdallah' \\ F El Younsi' \\ H Ben Maiz ${ }^{3}$ \\ A Kheder' \\ 'Internal Medicine Department, \\ ${ }^{2}$ Pediatric Department, ${ }^{3}$ Laboratory \\ of Kidney Diseases, Charles Nicolle \\ Hospital, Tunis, Tunisia
}

Correspondence: Mondher Ounissi Department of Internal Medicine A - Charles Nicolle Hospital, Boulevard du 9 Avril, 1006 BS - Tunis, Tunisia Tel +21671578483

$\mathrm{Fax}+21671560280$

Email mejid66@yahoo.fr
Introduction: Nephrolithiasis still remains a too frequent and underappreciated cause of end stage renal disease (ESRD).

Methods and patients: Of the entire cohort of 7128 consecutive patients who started maintenance dialysis in our nephrology department between January 1992 and December 2006, a total of 45 patients ( 26 women, 19 men) had renal stone disease as the cause of ESRD. The type of nephrolithiasis was determined in 45 cases and etiology in 42. The treatment and evolution of stone disease and patient's survival were studied.

Results: The overall proportion of nephrolithiasis related ESRD was $0.63 \%$. The mean age was 48.4 years. Infection stones (struvite) accounted for $40 \%$, calcium stones, $26.67 \%$ (primary hyperparathyroidism: $15.56 \%$; familial hypercalciuria: 4.44\%, unknown etiology: $6.66 \%$ ), primary hyperoxaluria type $1,17.78 \%$ and uric acid lithiasis in $15.56 \%$ of cases.

The mean delay of the evolution of the stone renal disease to chronic renal failure was 85.8 months. The feminine gender, obesity and elevated alkaline phosphatases $>128 \mathrm{IU} / \mathrm{L}$ were significantly correlated with fast evolution of ESRD. The median evolution to ESRD was 12 months. The normal body mass index (BMI), medical treatment of stone and primary hyperoxaluria type 1 were correlated with fast evolution to ESRD.

All patients were treated by hemodialysis during a mean evolution of 60 months. Sixteen patients died. The patient's survival rate at 1,3 and 5 years was $97.6,92.8$ and $69 \%$ respectively. Hypocalcemia, cardiopathy and normal calcium-phosphate product were significantly correlated with lower survival rate.

Conclusion: Severe forms of nephrolithiasis remain an underestimated cause of ESRD. These findings highlight the crucial importance of accurate stone analysis and metabolic evaluation to provide early diagnosis and efficient treatment for conditions leading to ESRD.

Keywords: Nephrolithoiasis, ESRD, struvite, dialysis, prevention

\section{Introduction}

The contribution of nephrolithiasis related to end stage renal disease (ESRD) in patients requiring renal replacement therapy has never been specifically evaluated. Nephrolithiasis still remains a too frequent and underappreciated cause of ESRD and this is all the most unfortunate since such prognosis is now preventable in most cases.

Infection stones, especially when bilateral developing a stag horn configuration are universally considered the most frequent cause of urolithiasis associated ESRD. ${ }^{1,2}$ Extensive stone development also has been observed with calcium-oxalate, uric acid or cystine stones and in patients with anatomic abnormalities of the urinary tract. ${ }^{3}$

In addition to the well known obstructive and infections mechanisms of kidney injury crystal deposition in the tubules and interstitium of both kidneys constitutes 
another, often underappreciated mechanism of progressive renal failure.

The potential risk of degradation of renal function justifies the etiological investigation of all lithiasis associated pathologies. Therefore calculus analysis of the crystalline phases and morphological characteristics is an important factor in the etiological diagnosis of the disease.

In the present study we reviewed the charts of all patients for whom urinary stone disease was recorded as the exclusive or preponderant cause of ESRD in the entire cohort of patients who started maintenance dialysis therapy at our nephrology department from 1992 to 2006 . We analyzed: the frequency of nephrolithiasis associated ESRD; distribution of various types of nephrolithiasis; their respective cause; treatment; and evolution. We reviewed also patient survival rate at 1, 3 and 5 years. These results were then compared to data contained in the literature.

\section{Patients and methods}

Of the entire cohort of 7128 consecutive patients who started maintenance dialysis therapy at our nephrology department between January 1992 and December 2006, a total of 45 patients ( 26 women, 19 men) had renal stone disease as the cause of ESRD and constitute the patients in this study. In all 45 patients urinary stone disease was the exclusive or preponderant cause of ESRD assessed by means of a detailed patient history, renal biopsy and exclusion of other possible causes of interstitial nephropathy and renal insufficiency. The cause of stone disease was identified on the basis of history, laboratory data and urinary crystal examination.

Stones that developed in patients who were on dialysis therapy were not considered in our study. The Cockcroft and Gault equation was used in the assessment of creatinine clearance.

Creatinine clearance $=\frac{(140-\text { age }) \times \text { weight }(\mathrm{kg})}{\text { Creatininemia }(\mu \mathrm{mol} / \mathrm{L})}$

This product should be multiplied by 1.23 for men. A renal failure is defined by a creatinine clearance lower than $80 \mathrm{~mL} / \mathrm{minute}$ and the end stage is retained if the creatinine clearance is lower than $10 \mathrm{~mL} /$ minute.

The statistical analysis was made using the Stat View Software 5.0. Categorical variables were compared using the unpaired student's T-test. Nominal variables were compared using chi square. The patient's survival rates were compared using the actuarial method and comparison was performed using logrank test. The level of statistical significance was at $5 \%$.

\section{Results}

The overall proposition of nephrolithiasis related ESRD among the total number of incident ESRD cases was $0.63 \%$ (ie, 45 of 7128 patients). Annual incidence was 3. Of the 45 patients, there were 19 men $(42.22 \%)$ and 26 women $(57.78 \%)$ with a gender ratio of 0.73 .

The mean age of the patients was $48.4 \pm 17.63$ years (range of 17-80). The majority of patients (32) originated from the north and the north west of Tunisia, (74.11\%); ie, $20(44.44 \%)$ and $12(16.67 \%)$ respectively. Eight patients originated from the central Tunisia $(17.78 \%)$ and 5 from the south $(11.11 \%)$.

Eleven patients had family antecedents of urinary lithiasis (24.45\%) and six of primary hyperparathyroidism type 1 . Twenty four patients had hypertension $(53.33 \%)$, six had diabetes (13.33\%) and four cardiopathy (8.89\%).

The Table 1 illustrates the discovering circumstances of nephrolithiasis. The diagnosis of nephrolithiasis stemmed from painful symptomatology, hematuria or urinary infection and was confirmed by radiology (x-ray-tomography-urography). Morphoconstitutional analysis, supplemented by biochemical and metabolic evaluation of nephrolithiasis, confirmed the nature and etiology of calculi. Tables 2 and 3 illustrate the composition and the etiologies of nephrolithiasis.

Thirty one patients were treated surgically: 15 had a lombotomy with lithotomy; 10 a unilateral nephrectomy, 3 a percutaneous nephrolithotomy and 3 treated with extracorporeal lithotripsy. The 14 remaining patients were treated medically. The median of evolution of the nephrolithiasis from nephropathy to chronic renal failure (CRF) was 24 months

Table I Discovering circumstances of nephrolithiasis

\begin{tabular}{lll}
\hline $\begin{array}{l}\text { Discovering } \\
\text { circumstances }\end{array}$ & $\begin{array}{l}\text { Number of } \\
\text { patients }\end{array}$ & Percentage \% \\
\hline Renal colic & 16 & 35.55 \\
Fortuitous discovery (radiology) & 8 & 17.78 \\
Lithiasis Emission & 5 & 11.11 \\
Urinary infection & 5 & 11.11 \\
Macroscopic Hematuria & 4 & 8.89 \\
Kidney Failure & 3 & 6.67 \\
Others & 4 & 8.89 \\
Total & 45 & 100 \\
\hline
\end{tabular}


Table 2 Composition of lithiasis and nature

\begin{tabular}{lll}
\hline Composition & Number of patients & Percentage \% \\
\hline Struvite & 18 & 40 \\
Calcium lithiasis & 12 & 26.67 \\
Oxalic lithiasis & 8 & 17.77 \\
Uric acid lithiasis & 7 & 15.56 \\
Total & $\mathbf{4 5}$ & 100 \\
\hline
\end{tabular}

(range 1-408 months). The evolution to CRF was faster in men than women (68 versus 109 months, $P=\mathrm{NS}$ ). The evolution of the condition in patients originating from the center of Tunisia rather than those from north (35.1 versus 124.8 months, $P=$ NS) or North West (35.1 versus 72.7, $P=\mathrm{NS})$. Patients with hypertension versus others without (59.1 versus 116.2 months $P=0.08$ ) without any statistically signification. The condition was also significantly faster in the event of diabetes (19.3 versus 96 months, $P=\mathrm{NS}$ ) or cardiopathy (18.75 versus $92.3, P=\mathrm{NS}$ ). Obesity defined by a body mass index (BMI) $\geq 30 \mathrm{~kg} / \mathrm{m}^{2}$ was correlated with a faster evolution to CRF (14.8 versus 99.7 months, $P=0.03)$.

The etiology of nephrolithiasis had no impact on this evolution. Surgical treatment slowed down the evolution of CRF compared to medical treatment (97 versus 61 months) without any statistically significance.

Alkaline phosphatases higher than 128 IU/L were significantly correlated with a faster evolution to CRF than those lower than $128 \mathrm{IU} / \mathrm{L}$ (57 versus 142.9 months, $P=0.011$ ) No correlation was found with the other phosphocalcic parameters (calcemia - phosphate, calcium - phosphate product and parathormone).

The final stage of CRF was reached after a median evolution of 12 months (range 1-156 months). The age, gender and geographic origin had no significant impact on the evolution to ESRD. Obesity was significantly correlated to the evolution to ESRD (71 versus 18 months, $P=0.015)$.

The patients having a parathyroid hormone (PTH) between 150 and $300 \mathrm{pg} / \mathrm{mL}$ evolved more quickly to ESRD than patients having secondary hyperparathyroidism (19.66 versus 36.6 months, $P=\mathrm{NS}$ ).

The nephrolithiasis etiology had no impact on the evolution to ESRD, nevertheless patients having primary hyperoxaluria type 1 evolved more quickly to ESRD than those having infectious (15.45 versus 31.7 months, $P=\mathrm{NS}$ ) or calcic nephrolithiasis (15.45 versus 41.3 months, $P=\mathrm{NS}$ ).
Table 3 Etiologies of nephrolithiasis

\begin{tabular}{lll}
\hline Etiology & $\begin{array}{l}\text { Number of } \\
\text { patients }\end{array}$ & Percentage \% \\
\hline Infectious lithiasis & 18 & 40 \\
Primary hyperparathyroidism & 7 & 15.56 \\
Familial hypercalciuria & 2 & 4.44 \\
Unknown calcic lithiasis etiology & 3 & 6.66 \\
Primary hyperoxaluria type I & 8 & 17.78 \\
Uric acid lithiasis & 7 & 15.56 \\
Total & $\mathbf{4 5}$ & 100 \\
\hline
\end{tabular}

The medical treatment of the lithiasis was significantly correlated to a faster evolution to ESRD compared to urological treatment (8.75 versus 53.2 months, $P=0.04$ ). All patients were treated by hemodialysis. The median duration of dialysis was 59 months (range 1-169 months). Osteoarticular complications occurred in $91.11 \%$ of patients ( secondary hyperparathyroidism $=55.56 \%$ and adynamic bone disease in $35.56 \%$ of patients) and cardiovascular in $66.67 \%$ (cardiac failure: $22.22 \%$, coronaropathy $20 \%$ and heartbeat rate disorders $22.3 \%$ ).

Sixteen patients died. The Table 4 illustrates the causes of death. The patient's survival rate at 1, 2, 3 and 5 years was: $97.6 \% ; 95 \% ; 92.8 \%$; and $69 \%$ respectively and this was $96 \% ; 95.2 \% ; 90 \%$; and $71 \%$ for all dialyzed patients. Age, gender, geographic origin, hypertension, BMI had no impact on patient's survival or nephrolithiasis etiology. Patient survival at 5 years was significantly combined with cardiopathy (33\% versus $72 \%, P=0.06)$, hypocalcemia (56\% versus $100 \% . P=0.014)$, normal calcium phosphorus product $(53 \%$ versus $92 \% P=0.0084$ ). The other phosphocalcic parameters had not any impact on patient survival. The faster evolution to the ESRD ( $\leq 31.5$ months) was significantly correlated

Table 4 The causes of death

\begin{tabular}{lll}
\hline $\begin{array}{l}\text { Cause of } \\
\text { death }\end{array}$ & $\begin{array}{l}\text { Number of } \\
\text { patients }\end{array}$ & Percentage (\%) \\
\hline Sudden death & 6 & 37.5 \\
Septic shock & 4 & 25 \\
Acute pulmonary Edema & $\mathrm{I}$ & 6.25 \\
Hypokalemia & $\mathrm{I}$ & 6.25 \\
Cachexia & $\mathrm{I}$ & 6.25 \\
Stroke & $\mathrm{I}$ & 6.25 \\
Myocardial infarction & $\mathrm{I}$ & 6.25 \\
Tuberculous spondylodiscitis & $\mathrm{I}$ & 6.25 \\
Total & 16 & 100 \\
\hline
\end{tabular}


with longer survival at 7 years compared to slower evolution (>31.5 months).

\section{Discussion}

End stage renal disease caused by urinary stone disease, although accounting for a limited proportion of cases, still remains a problem that should not be overlooked.

The principal mechanisms involved in the development of renal failure in patients with nephrolithiasis were recurrent stone formation, obstruction of the excretory tract and extensive crystal deposition in the renal parenchyma. Irreversible renal impairment was observed essentially in patients with a delayed diagnosis, suboptimal urological and medical management, or intrinsically severe forms of stone disease. ${ }^{4,5}$ Severe forms of nephrolithiasis remain an underestimated cause of potentially avoidable ESRD and the need renal replacement therapy. ${ }^{6}$

In our experience, nephrolithiasis related ESRD contributed $0.63 \%$ to the total series of patients who started maintenance dialysis therapy at our department of nephrology during a 15 year period. These figures are in agreement with those extracted from recent the United States Renal Data System data. Among 228,332 white patients who started renal replacement therapy in the US from 1993 to 1997 , a total of $1.5 \%$ were categorized as having "nephrolithiasis, obstruction, gouty " as the primary renal disease, thus leading to an estimated incidence of 2.9 patients/year. Paul Jungers and colleagues have reported that the overall proportion of nephrolithiasis related ESRD was 3.2\%. ${ }^{6}$ Another estimation can be extracted from a prospective epidemiological inquiry conducted at all nephrology and dialysis units in the Ile de France area, which has a total population of 10.7 million inhabitants. Of 1060 adult patients who started maintenance dialysis therapy in 1998, nephrolithiasis was recorded as the cause of ESRD in $1.8 \%$ of cases. ${ }^{7}$ In a cohort of 171 patients with severe idiopathic calcium stone disease reported by Marangella and colleagues 18\% had mild renal insufficiency but no patients reached ESRD during a mean follow up of 3.5 years. ${ }^{8}$ Of 2000 consecutive unselected stone formers reported by Gupta and colleagues only 33 patients $(1.7 \%)$ had mild to moderate renal failure. ${ }^{9}$ A very low frequency of progressive renal failure was reported in other studies. Of 3266 patients with nephrolithiasis reported recently by Worcester and colleagues none developed ESRD and there was no significant decline in creatinine clearance between the first and the last visit. ${ }^{2}$ Jungers reported that the frequency of nephrolithiasis related ESRD significantly decreased with time; from an average proportion of $4.7 \%$ from 1989 to 1991 to $2.2 \%$ from 1998 to 2000 . $^{6}$

In our study, the rate of ESRD, due to nephrolithiasis, was the prerogative of the fifty years old adult patients with female prevalence. In a Moroccan study including 183 patients, Oussama and colleagues reported that the average age was 60 years with clear male prevalence. ${ }^{10}$ Coe and colleagues found the similar results. ${ }^{11}$ The potential risk of degradation of renal function highlights the crucial importance of accurate stone analysis and metabolic evaluation to provide early diagnosis and the correct therapy for conditions that may lead to ESRD.

In our study, morphoconstitutional analysis of calculi from 45 patients showed that struvite was the main component in $40 \%$ of cases. In all these patients, disease onset occurred a long time ago, before the modern era of urological treatment. This cause of stones has been reported in other studies: Jungers in $36 \%{ }^{6}$ and Gupta in $64 \%$ of cases. ${ }^{9}$

However many authors reported that the frequency of this cause will decrease in the future because of earlier diagnosis and easier urological management. ${ }^{12}$ Struvite accounted for $15.3 \%$ of nephrolithiasis among 183 patients for Oussama and colleagues. ${ }^{10}$ The female prevalence noted in our series was also found by Gupta ${ }^{9}$ although not by Oussama. ${ }^{10}$

In children, Daudon and colleagues noted that struvite frequency was $9.9 \%$ of cases. ${ }^{13}$ Although responsible for ESRD in nearly $26.67 \%$ of our patients, calcium stones appear to be an infrequent cause of ESRD compared with the very large number of calcium stone formers. Its frequency was $26.7 \%$ for Jungers and even higher for Oussama in $58.5 \%$ of cases. ${ }^{6,10}$

In our experience, such an outcome is mainly caused by late diagnosis in patients with primary hyperparathyroidism (58.83\%) and idiopathic hypercalciuria (16.66\%) resulting in multiple stone episodes; with the aggravating influence of recurrent urinary tract infection in several patients.

Among 12 calcium stones reported by Jungers, heavy hypercalciuria was present in 33\% of cases, primary hyperparathyroidism in $16.66 \%$ and medullary sponge kidney in $41.67 \%$ of cases. ${ }^{6}$ In our study the etiology was not identified in $6.66 \%$ of cases. This frequency was much less than that of Gupta with $59 \%$ of cases. ${ }^{9}$

Uric acid nephrolithiasis accounted for $15.56 \%$ of cases in our study; however in western literature, it represented by $7.2 \%$ to $15.3 \%$ of cases. ${ }^{14-16}$ This figure was $17.8 \%$ for Jungers and $18 \%$ for Oussama. ${ }^{6,10}$ It does seem that this type of calculi is more frequent in North Africa than in Europe or US, suggesting the influence of nutritional factors. ${ }^{10}$ 
There was a male prevalence in our series and also for Oussama. ${ }^{10}$ Primary hyperoxaluria type 1 (PH1) is frequently misdiagnosed, especially when urinary stones manifest first in adult patients or if early symptoms are misinterpreted. ${ }^{6}$ It accounted for $17.78 \%$ of nephrolithiasis in our study. This frequency was largely higher than that of Jungers. ${ }^{6}$ A very low frequency of progressive renal failure especially ESRD was reported.

Of 3266 patients with nephrolithiasis reported by Worcester and colleagues none developed ESRD and there was no significant decline in creatinine clearance between the first and the last visit (2). In our experience, the evolution of nephrolithiasis nephropathy to chronic renal failure (CRF) was paradoxically very fast, with a median of 24 months. This figure was of 7 years for Teichmann ${ }^{17}$ and 4 years for Coe. ${ }^{11}$ In agreement with the results of Giovanni, ${ }^{18}$ the median evolution was shorter among women. Hypertension and obesity were significantly correlated with a faster evolution to CRF.

There was no significant correlation found with calcemia, phosphatemia, calcium phosphate product, parathormone and hemoglobin. However alkaline phosphatases levels superior to $128 \mathrm{IU} / \mathrm{L}$ were correlated with faster evolution to CRF.

In agreement with Steven's results. ${ }^{19}$ urological treatment allowed the slackening of the evolution to CRF compared to the symptomatic treatment in our series. The end stage of renal insufficiency was reached after a median of 12 months in our patients. Singh and colleagues reported that 14 patients among 20 with nephrolithiasis evolved to ESRD in a time lower that one year. ${ }^{20}$

Contrary to the age, gender and geographical origin which had no impact on the evolution to ESRD, obesity was significantly associated with a slower evolution. This result was also reported by Daniel. ${ }^{21}$ Secondary hyperparathyroidism and urological treatment were associated with slower evolution to ESRD. In the experience of Teichmann, all patients treated medically suffered a deterioration in their renal function against only $28 \%$ of surgically treated patients. ${ }^{17}$ The etiology of nephrolithiasis had no impact on the evolution to ESRD among our patients, nevertheless those having primary hyperoxaluria type 1 (PHA1) developed faster ESRD than those having a struvite or a primary hyperparathyroidism.

All our patients were treated by hemodialysis during a median evolution of 60 months. Sixteen patients died because of cardiovascular and infectious complications. The patient's survival rate at 1,2, 3 and 5 years was respectively $97.6 \%$, $95 \%, 92.8 \%$ and $69 \%$, which was comparable with the survival rate of the totality of dialyzed patients.
No data concerning patient's survival was found in the literature. The age, gender and geographical origin had no impact on the patient's survival rate. O'Connor and colleagues showed that advanced age is a risk factor of renal function deterioration and mortality among patients having nephrolithiasis related ESRD. ${ }^{22}$ Hypertension had no impact on the patient's survival rate, whereas cardiopathy was associated with lower rate at 5 years.

Contrary to the results of Danie ${ }^{21}$ we did not find any statistical correlation between the BMI and the patient survival rate. The nephrolithiasis etiology also had no impact on patient survival.

The fast evolution to ESRD ( $\leq 31.5$ months) was significantly associated with a better survival compared to the slow evolution ( $>31.5$ months). The evolution to CRF can be prevented with an early etiologic diagnosis of nephrolithiasis and an appropriate treatment. However severe forms of renal stone disease are much less frequent that the common benign forms. This must be kept in mind in view of the disastrous consequences that may result from delayed or improper diagnosis and treatment. ${ }^{23}$ In this regard, adequate analysis of stones and/or crystalluria together with proper metabolic evaluation are of crucial diagnosis value. They should never be neglected, especially in patients with the onset of nephrolithiasis in childhood, severely recurrent stones, nephrocalcinosis or incipient renal insufficiency as noted by Gambaro and colleagues. ${ }^{3}$ To this end the patient should be involved in the care of the nephrolithiasis.

The installation of medical software containing different clinical, biological and morphologic data accessible to all physicians from all specialties allows better coordination of the patient's care.

\section{Conclusion}

Nephrolithiasis remains the cause of potentially avoidable ESRD in too many patients despite recent major advances in the diagnosis and management of patients forming stones. These findings highlight the crucial importance of accurate stone analysis and metabolic evaluation to provide early diagnosis and proper therapy for a condition that may lead to ESRD through recurrent stone formation and/or crystal infiltration. ESRD and renal replacement therapy should be prevented in the future in most patients with renal stone disease.

\section{Disclosure}

The authors report no conflicts of interest in this work. 


\section{References}

1. Streem SB. Long term incidence and risk factors for recurrent stones following percutaneous nephroslithotomy or percutaneous nephroslithotomy/extracorporeal shock wave lithotripsy for infection related calculi. J Urol. 1995;153:584-587.

2. Worcester E, Parks JH, Josephson MA, et al. Causes and consequences of kidney loss in patients with nephrolithiasis. Kidney Int. 2003;64: 2204-2213.

3. Gambaro G, Favaro S, D'Angelo A. Risk for renal failure in nephrolithiasis. Am J Kidney Dis. 2001;37:233-243.

4. Le Normand L, Buzelin JM, Bouchot O, et al. Voie excrétrice supérieure: physiologie, physiopathologie des obstructions et explorations fonctionnelles. Ann Urol. 2005;39:30-48.

5. Rieu P. Lithiases d'infection. Ann Urol. 2005;39:16-29.

6. Jungers P, Joly D, Barbey F, et al. ESRD caused by nephrolithiasis: Prevalence, Mechanisms and Prevention. Am J Kidney Dis. 2004;44: 799-805.

7. Jungers P, Choukroun G, Robino C, et al. Epidemiology of end-stage renal disease in the Ile-de-France area: a prospective study in 1998. Nephrol Dial Transplant. 2000;15:2000-2006.

8. Marangella M, Bruno M, Cosseddu D, et al. Prevalence of chronic renal insufficiency in the course of idiopathic recurrent calcium stone disease : risk factors and patterns of progression. Nephron. 1990;54:302-306.

9. Gupta M, Bolton DM, Gupta PN, et al. Improved renal function following aggressive treatment of urolithiasis and concurrent mild to moderate renal insufficiency. J Urol. 1994;152:1086-1090.

10. Oussama A, Kzaiber F, Mernari B, et al. Analyse des calculs urinaires de l'adulte dans le moyen Atlas marocain par spectrophotométrie infra rouge à transformée de Fourier. Progrès en Urologie. 2000;10: 404-410.

11. Coe FL, Evan A, Worcester E. Kidney stone disease. J Clin Invest. 2005;115:2598-2608.
12. Segura JW, Preminger GM, Assimos DG, et al. Nephrolithiasis Clinical Guidelines Panel summary report on the management of staghorn calculi. The American Urological Association Nephrolithiasis clinical Guidelines Panel. J Urol. 1994;151:1648-1651.

13. Daudon M. L'analyse morphoconstitutionnelle des calculs dans le diagnostic étiologique d'une lithiase urinaire de l'enfant. Arch Pediat. 2000;7:855-865.

14. Brien G, Schubent G, Bick C. 10000 analysis of urinary calculi using X-ray diffraction and polarizing microscopy. Eur Urol. 1982;8: 251-256.

15. Daudon M, Donsomni R, Hennequin C, et al. Sex and age related composition of 10617 calculi analysed by infrared spectroscopy. Urol Res. 1995;23:319-326.

16. Herring LC. Observations of the analysis of ten thousand urinary calculi. J Urol. 1962;88:545-562.

17. Teichman JM, Long RD, Hubert JC. Long term renal fate and prognosis after staghorn calculus management. J Urol. 1995;153:1403-1407.

18. Giovani G, Silvana F, Angela A. Risk for renal failure in nephrolithiasis. AJKD. 2001;37:233-243.

19. Steven B, Michael A. Combination therapy for staghorn calculi in solitary kidneys. J Urol. 1993;149:449-452.

20. Singh I, Gupta NP, Hemal AK, et al. Efficacy and outcome of surgical intervention in patients with nephrolithiasis and chronic renal failure. Int Urol Nephrol. 2001;33:293-298.

21. Daniel F, Philippe D. Maladies rénales. Paris: Herman. Editeurs des sciences et des arts, 1992.

22. O'Connor RC, Worcester EM, Evan AP, et al. Nephrolithiasis and nephrocalcinosis in rats with small bowel resection. Urol Res. 2005;33:105-115.

23. Daudon M, Bader CA, Jungers P, et al. Urinary calculi: Review of classification methods and correlations with etiology. Scanning Microsc. $1993 ; 7: 1081-1104$

\section{Publish your work in this journal}

The International Journal of Nephrology and Renovascular Disease is an international, peer-reviewed open-access journal focusing on the pathophysiology of the kidney and vascular supply. Epidemiology, screening, diagnosis, and treatment interventions are covered as well as basic science, biochemical and immunological studies. The journal welcomes original research, clinical studies, reviews \& evaluations, expert opinion and commentary, case reports and extended reports. The manuscript management system is completely online and includes a very quick and fair peerreview system, which is all easy to use. Visit http://www.dovepress.com/ testimonials.php to read real quotes from published authors. 